\title{
The Importance of Longitudinal Neurocognitive Assessments in Heart Failure Patients Receiving a Left Ventricular Assist Device
}

\author{
Sneha Raju1,3*, Vanessa Rojas-Luengas, HBSc, MSc $(C)^{1,2 *}$ \\ ${ }^{1}$ Multi-Organ Transplant Program, University Health Network, Toronto General Hospital \\ Institute of Medical Science, University of Toronto \\ ${ }^{3}$ Faculty of Medicine, University of Toronto \\ *Both authors made equal contribution to the paper
}

A B STRACT

Heart failure (HF) is a major global health concern that has continued to increase in incidence and prevalence, becoming a global epidemic. In Canada alone, there are 500,000 HF patients, with 50,000 new cases each year. Often, HF patients reach severe end stage HF (ESHF) and require a heart transplant or a left ventricular assist device (LVAD). Previous studies have shown that as the heart begins to fail, ESHF patients develop a global cognitive impairment (CI) that accompanies the reduction in blood pressure (BP) and cardiac output (CO). Several mechanisms have been attributed to the Cl observed in ESHF patients. Cerebral hypoperfusion, due to a large decrease in $\mathrm{CO}$, appears to be the most supported explanation. Although several studies to date have explored cognitive functioning after the treatment of HF, there is limited literature investigating the cognitive outcome in ESHF patients following LVAD implantation. Moreover, studies that examined the effect of LVAD implantation on cognition did not compare patient outcomes to pre-LVAD baseline levels. Taking into consideration the increasing number of EDHF patients in need of LVAD implantation each year, it is imperative to determine the effect of this intervention on $\mathrm{Cl}$ in order to better inform LVAD patients and create effective rehabilitation programs for LVAD recipients.

\section{RÉSUMÉ}

L'insuffisance cardiaque (IC) est une préoccupation majeure de santé mondiale qui continue d'augmenter en incidence et en prévalence, devenant une épidémie mondiale. Au Canada seulement, 500000 patients souffrent d'IC, avec 50000 nouveaux cas chaque année. Souvent, les patients avec IC atteignent une phase terminale grave (ICT) et nécessitent une transplantation cardiaque ou un dispositif d'assistance ventriculaire gauche (DAVG). Des études antérieures ont démontré que lorsque le cœur est en insuffisance, les patients développent une déficience cognitive globale (DCG), accompagnant la réduction de la tension artérielle et du débit cardiaque. Plusieurs mécanismes ont été attribués à la DCG observée chez les patients en ICT. L'hypoperfusion cérébrale, en raison d'une diminution importante du débit cardiaque, semble être l'explication la plus soutenue. Bien que plusieurs études à ce jour ont exploré le fonctionnement cognitif suivant le traitement de I'IC, il existe une littérature limitée enquêtant le résultat cognitif chez les patients en ICT suivant l'implantation d'un DAVG. Par ailleurs, les études qui ont examiné l'effet de l'implantation de DAVG sur la cognition ne comparaient pas les résultats des patients avec leurs niveaux de base pré-DAVG. Prenant en considération le nombre croissant de patients en ICT en besoin d'implantation de DAVG chaque année, il est impératif de déterminer l'effet de cette intervention sur la DCG afin de mieux informer les patients avec DAVG et créer des programmes efficaces de réhabilitation pour les bénéficiaires de DAVG.

\section{INTRODUCTION}

Heart failure (HF) is a global epidemic carrying a lifetime risk of $20 \%[1,2]$. Heart failure is defined as a physiological state in which there is insufficient cardiac output (CO) to satisfy the body's needs. In the prospective cohort Rotterdam study, the prevalence of HF increased as patients got older from $0.9 \%$ in 55 -year-olds to $17.4 \%$ in those over 85 years of age $[2,3]$. While medical therapies have been able to reduce morbidity and mortality, the overall incidence and prevalence of HF continues to rise. Over 500,000 people suffer from HF in Canada, with 50,000 new cases per year [4]. 40-50\% of these patients have a lifespan of less than five years [4-7]. Furthermore, the average an- nual mortality rate is $5-10 \%$ depending on age, co-morbidities, and severity of symptoms. In severe end stage HF patients, once medical therapy ceases to control symptoms, patients often require advanced mechanical therapies such as left ventricular assist devices (LVAD) or cardiac transplant $[8,9]$.

Although HF affects the circulatory system at first, it can eventually have detrimental effects on the nervous system. During the initial stages of HF, the carotid baroreceptors detect a fall in arterial blood pressure (BP), resulting in increased vasoconstriction. Although this may initially restore BP, it can increase peripheral resistance, augmenting heart workload. Over time, the heart will begin to fail, leading to a generalized reduction in BP and

Keywords: Cardiac; Surgery; End stage heart failure; LVAD; Transplant; Cognitive functioning; Chronic; ADL; Readmissions 
CO $[10,11]$. Previous studies have shown that cerebral blood flow is substantially decreased, on average, by $31 \%$ in patients with ESHF. This hypoperfusion can be attributed to the generalized hypotension that accompanies $\mathrm{HF}$, and can affect a vast number of cortical functions.

\section{COGNITIVE FUNCTIONING IN END STAGE HEART FAILURE (ESHF)}

Cognition is a collective term for higher cortical functions such as thinking, remembering, planning, knowing, and analyzing [12]. Cognitive functioning incorporates several cognitive domains including memory, attention executive functioning, psychomotor speed, language, and visuospatial ability [12-14]. Functional magnetic resonance imaging (MRI) and positron emission tomography (PET) studies have shown that individual cognitive domains involve diverse, overlapping regions of the brain [15-17]. Several methods are used to measure cognitive functioning, from the mini-mental state examination (MMSE), which measures global cognition and is used by physicians at the bedside, to more detailed neuropsychological assessments that examine individual domains.

Cognitive impairment $(\mathrm{Cl})$, or a decline in one or more cognitive domains, is common in ESHF [18-21]. A landmark paper in Lancet published in 1997 was one of the first studies to coin the term "cardiogenic dementia" and identify a link between $\mathrm{Cl}$ and cardiac disease [22]. The prevalence of $\mathrm{Cl}$ in $\mathrm{HF}$ patients varies from $25 \%-58 \%$ [23-26]. This wide range is due to varying study designs, severity of heart failure, diagnostic criteria, and battery of neuropsychological tests utilized. Due to their $\mathrm{Cl}, \mathrm{HF}$ patients have poor somatic awareness, reduced independence, and decreased ability to carry out activities of daily living. Since HF patients have decreased ability to care for themselves, they are at higher risk of mortality, morbidity, re-hospitalization, and worsening HF [27]. Most patients suffering from $\mathrm{Cl}$ secondary to $\mathrm{HF}$ are diagnosed with mild impairment while around $25 \%$ have moderate to severe $\mathrm{Cl}$ [27]. Treatments such as angiotensin converting enzyme (ACE) inhibitors and physical activity have resulted in cognitive rehabilitation [28]. In the past, cognitive rehabilitation has been defined as the improvement of cognitive functioning in either global cognitive functioning or specific domains. Such studies suggest that $\mathrm{Cl}$ in $\mathrm{HF}$ can potentially be improved up to a certain degree.

\section{DOMAIN SPECIFIC COGNITIVE IMPAIRMENTS IN HEART FAILURE}

It is important to review existing literature on domain-specific $\mathrm{Cl}$ in heart failure patients. Inconsistencies among studies in regards to the prevalence of $\mathrm{Cl}$ and the domains involved may be due to the fact that most studies have used a wide variety of neuropsychological tests $[19,27]$.

\section{MEMORY}

Memory refers to the capacity to retain information and utilize it for adaptive purposes [29]. Registration, storage, and retrieval are the three main stages involved in memory [29]. Impaired memory isolates patients from meaningful contact with the world around them and renders them dependent on others. Even mildly to moderately impaired memory can be debilitating [29]. Memory testing is often carried out through an interview in which patients are asked about their personal lives and public events. Then, the California Verbal Learning Test (CVLT) and Rey Auditory Verbal Learning Test (AVLT) are used, in which patients learn a list of words that they are later asked to recall [27, 30]. Several studies have demonstrated HF patients' impaired cognitive performance on both initial learning and delayed recall tests [16, 31-38]. In contrast, other studies did not show a reduction in initial learning scores $[27,39-40]$.

\section{LANGUAGE}

There are many possible language deficits that HF patients may experience. These deficits may include difficulties in word finding and naming [29]. Patients may have impairment in word recognition when reading, use related words instead of the intended word (semantic aphasia), and have trouble following instructions and maintaining a conversation [31]. Neurocognitive assessments used to examine this domain in HF patients include naming, repetition, following commands, reading, writing, and verbal fluency tests. There are two main studies, both of which found impaired performance on language parameters in patients with HF [16, 32]. They used the Boston Naming Test (BNT), Benton Controlled Oral Word Association Test (COWAT), Token Test, and semantic fluency task. These have all been previously shown to be excellent indicators of changes in language functioning [ 41 , 42].

\section{EXECUTIVE FUNCTIONS}

Executive functioning enables a person to engage successfully in independent, purposeful, self-directed, and self-serving behavior [29]. This domain involves verbal reasoning, problem solving, planning, multi-tasking, managing novelty and cognitive flexibility [33]. It is especially important because when impaired, even partially, one may not be able to self-care, work independently, or maintain social relationships, irrespective of how well preserved other cognitive domains are [33]. Thus, executive functioning is often defined as the cognitive abilities required to carry out activities of daily living. Executive function can be tested using a variety of methods, but the most popular one is the Trail Making $B$, in which the patient connects the dots between numbers and letters as fast as possible. There have been many studies looking at executive functioning in HF patients, and the majority have found significant impairments [34-40, 43]. There were two studies that did not find any differences in executive functioning [16, 
44]. However, these studies used a different battery of neuropsychological assessments.

\section{ATTENTION, WORKING MEMORY, AND PSYCHOMOTOR SPEED}

Attention refers to processes that allow us to be receptive to stimuli and to how we process incoming stimuli $[29,45]$. It allows us to concentrate and focus on stimuli of our choosing without being distracted by extraneous events. Working memory, which is what allows us to maintain and manipulate information for short periods of time, is a function of attention and relates to information processing [45]. The digit span and Trail Making Test A are commonly used to assess attention and working memory [12]. Psychomotor speed is the speed at which we process information and react to stimuli $[29,46]$. Deficits in all three (attention, working memory and psychomotor speed) are commonly seen in patients with vascular, sub-cortical and multi-infarct dementia [47]. Most studies employed the Digit Symbol Substitution Test (DDST) to assess changes in psychomotor speed. Patients with severe $\mathrm{HF}$ were shown to have significant deficits in attention, working memory, and speed of processing in the majority of studies [20, $32,34,35,38,39,44,49-51]$. However, there were a few studies that failed to show significant changes $[35,49,52,53]$. The profile of deficits seen in HF patients shares a lot of commonalities with that of vascular dementia, but it is different from that of neurodegenerative dementia. This pattern seems to indicate that the former two clinical syndromes share similar pathophysiologic mechanisms.

\section{VISUOSPATIAL FUNCTION}

Visuospatial function describes visual perception of both the environment as a whole and the spatial relationships between objects [29]. It is used when we are getting dressed, grasping objects or trying to orient ourselves [29]. The most commonly used neuropsychological tests to ascertain changes in visuospatial function include the Benton Facial Recognition Test (FRT), Judgment of Line Orientation Test (JLO), and the Clock Drawing Test (CDT) [12]. While there have not been many studies looking at visuospatial function in HF patients, most found visuospatial deficits $[36,49]$. There was a single study that suggested no differences in this domain for HF patients [32].

\section{PATHOGENESIS OF CI IN HF}

While there are several potential mechanisms explaining the $\mathrm{Cl}$ that often accompanies HF, decreased cardiac output leading to cerebral hypoperfusion and in turn, neuronal degeneration is the most likely model [10, 54-57]. The Critically Attained Threshold of Cerebral Hypoperfusion (CATCH) hypothesis asserts that heart failure causes early vascular aging, leading to orthostatic hypotension, stroke, intracranial atherosclerosis, and small vessel disease [10]. Thus, the story appears to be more complex than a simple link between hypotension and $\mathrm{Cl}$.

While hypotension can impair cognitive functioning, hypertension has also been shown to play a role in cognitive decline. The surprising evidence that both extremes are implicated in cognitive decline may be explained by the concept of neurovascular coupling (NC) [11]. NC refers to interactions between endothelial cells, neurons, and other cells of the nervous system [58]. These interactions are responsible for ensuring that highly active areas of the cerebral cortex obtain adequate perfusion while perfusion of inactive areas decreases. The capacity of the NC system to respond to BP variations and increased metabolic demand is referred to as the brain vascular reserve (BVR). Patients with hypotension and/or hypertension have been shown to have decreased BVR and poor cerebral auto-regulation [11, 55].

Cerebral auto-regulation maintains stable perfusion over a 60 to $150 \mathrm{mmHg} B P$ range $[11,59]$. Thus, the auto-regulation curve plotting cerebral blood flow (CBF) against mean blood pressure assumes a sigmoid shape with the areas outside the auto regulatory ranges adopting an almost linear relationship. Conditions such as hypertension, hypotension, diabetes, stroke, and vascular disease can impair auto-regulation, leading to a near linear relationship [60-63]. With a linear relationship, cerebral perfusion becomes pressure-dependent. Importantly, many patients with end stage heart failure suffer from one or more of the aforementioned conditions [11].

Since patients in severe $\mathrm{HF}$ tend to be hypotensive at the time of LVAD implantation, it is pertinent to look at the following literature. There have been three major studies to date looking at the effects of hypotension on cognitive functioning: ARIC, MPP and the Helsinki Ageing study [64-66]. All three studies found that hypotension leads to poorer results on cognitive tests (neuropsychological tests and the MMSE). The mean follow up time of these studies was thirteen years. The cerebral perfusion in a hypotensive patient is fully dependent on the mechanisms of autoregulation [11]. Thus, hypoperfusion can result when BP is low (below the range where autoregulation is possible) or when there is impaired auto-regulation. In patients with chronically low BP (less than 120/70), having orthostatic hypotension increases the probability of developing cognitive impairment [67]. Conversely, it has been shown that the presence of orthostatic hypotension in hypertensive patients reduces the odds of developing $\mathrm{Cl}$ [68].

There are a variety of factors mediating cerebral perfusion. A number of these factors have been implicated in cognitive changes in the context of hypotension. Low $\mathrm{CO}$ has been correlated with reductions in cognitive performance and increased incidence of dementia [27] while low systolic blood pressure has also been shown to be a predictor of cognitive impairment level in HF patients [69]. Lastly, cerebrovascular reactivity, which is the ability of cerebral vessels to change diameter to maintain CBF, is impaired in HF patients, correlating with the degree of HF [27]. 
These findings give further credence to perfusion abnormalities as the link between $\mathrm{Cl}$ and $\mathrm{HF}$.

Ample radiological evidence implicates systemic hemodynamics in the $\mathrm{Cl}$ observed in $\mathrm{HF}$ patients. One study showed that $\mathrm{CBF}$ was reduced by $30 \%$ in patients with severe HF [15]. Another study showed that the degree of $\mathrm{Cl}$ was related to regional reduction in CBF to certain brain regions, especially to the posterior cortical areas [16]. These results suggest that cognitive impairment in HF patients is closely related to cerebral perfusion measures. Additionally, there are multiple studies examining the effects of reduced cerebral perfusion, as measured using Doppler imaging, on cognitive decline [70-72]. Moreover, Zuccala et al. found a linear relationship between MMSE scores and left ventricular ejection fractions lower than $40 \%$ [73]. Finally, a different study revealed associations between CO and Trail B, Digit Symbol Substitution, and Stroop Test scores [74].

\section{LVAD AND COGNITIVE REHABILITATION}

Limited literature exists on neurocognitive assessments in advanced heart failure patients receiving LVADs (Figure 1). As this patient population continues to grow, it is important to document changes in cognitive performance, as this may predict patients' future health outcomes. Petrucci et al. looked at cognitive functioning post-LVAD at one, three and six months [42]. They assessed five neurocognitive domains using tests for (1) visual-spatial perception (Clock Drawing, Wechsler Adult Intelligence Scale III Block Design), (2) memory (Wechsler Memory Scale III-Logical Memory and Visual Reproduction), (3) executive functions (Trail Making B, WAIS III Digit Symbol), (4) language (Boston Naming Test), and (5) processing speed (Trail Making A) [42]. They found significant improvements in visual memory, executive functions, visual spatial perception, and processing speed over the sixmonth span. Results for the other assessments remained stable. While these are promising results, it is crucial to note that the study did not control for stress, depression, and pre-morbid estimates of IQ. All of these parameters have been shown previously to impact results of neurocognitive testing. In addition, while they showed improvement of cognitive functioning post-LVAD implantation, it is also necessary to examine differences in cognitive functioning pre- and post-surgery.

\section{COGNITIVE FUNCTION AND BRAIN TISSUE OXYGEN SATU- RATION}

Although $\mathrm{Cl}$ in $\mathrm{HF}$ patients is believed to be largely due to hypoperfusion, monitoring of tissue oxygen saturation is not a priority during LVAD implantations. Although hemodynamic and respiratory monitors are employed during cardiac surgery to improve patient safety, little has been done to monitor cerebral function and perfusion during surgery. Increased adverse events pertaining to the central nervous system (including strokes and cognitive deficits) lead to increased mortality, length of hospitalization, and poor long-term outcomes [78]. The etiologies of these complications are known to be multifold. First, in surgeries using the cardio-pulmonary bypass machine (CPB) such as LVAD, coronary artery bypass, and heart transplantation, there are increased rates of embolization of gaseous and particulate emboli from the surgical site, as well as from placement and removal of the aortic cross clamp [79]. Second, there is transient hypoperfusion due to loss of cerebral autoregulation, which may lead to cortical damage $[79,80]$. All of these mechanisms may result in tissue ischemia, leading to neuronal degeneration. There are a few options available to monitor cerebral oxygen saturation levels in order to detect ischemia. Most of these options are either invasive (jugular bulb saturations) or inaccurate (EEG, because the recordings are distorted by the isoelectricity caused by hypothermia/anesthetic agents). Cerebral oximetry, however, is a reasonable option as it is not invasive, and is not influenced by anesthetic agents $[1,82]$

A few studies have examined the relationship between neurocognitive dysfunction and tissue oxygen saturation. Yao et al. found that perioperatively, patients with a cerebral oxygen saturation of less than $40 \%$ for over 10 minutes had increased incidence of neurocognitive dysfunction as measured by MMSE and the anti-saccadic eye movement test (ASEM) during cardiac surgery [83]. Murkin et al. investigated a prospective, randomized trial of 200 cardiac surgical patients and found that maintaining cerebral oxygen saturations over $75 \%$ of baseline decreased major organ morbidity and mortality [84]. Furthermore, studies in cardiac patients have shown that oxygen saturations in the perioperative stages are predictive of the incidence of postoperative cognitive dysfunction $[85,86]$. Thus, perioperative factors can impair the

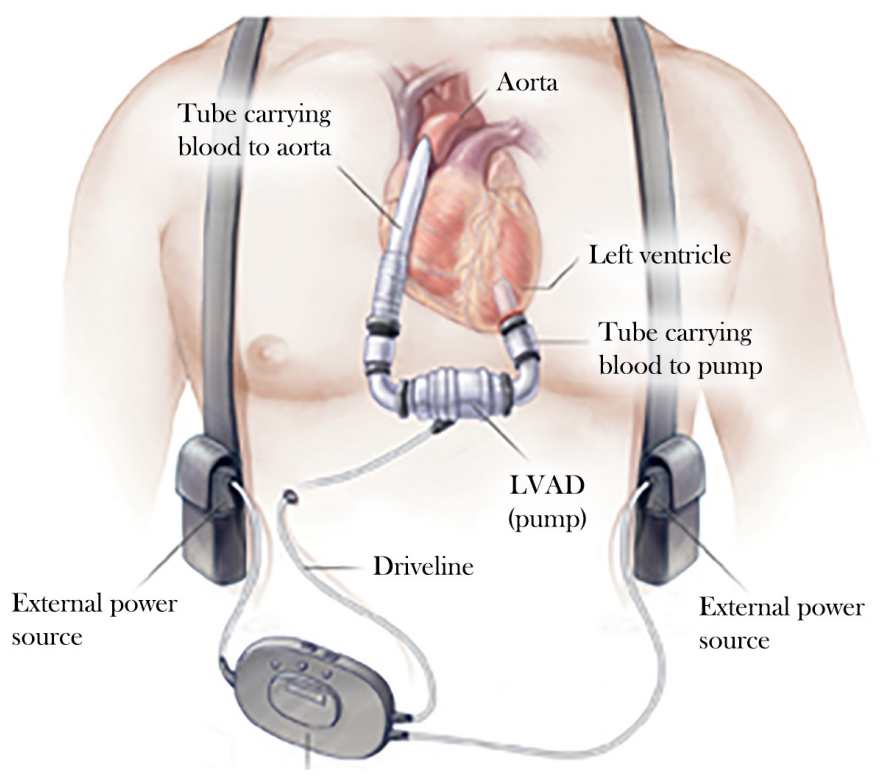

Figure 1. Left Ventricular Assist Device (LVAD) is one of the major interventions for severe end stage heart failure (ESHF). Further studies are needed to determine whether LVAD implantation leads to a decrease in cognitive impairment in ESHF patients. Image credit <http://www.mayoclinic.org/medical-professionals/ clinical-updates/cardiovascular/mayo-pioneers-innovative-treatment-patientsend-stage-cardiac-disease> 
potential for cognitive rehabilitation. However, the relationship between perioperative cerebral tissue oxygenation and cognitive rehabilitation has not been sufficiently explored in LVAD patients.

\section{FINAL WORDS}

In conclusion, the effect of LVAD implantation on patient cognition remains elusive. Although recent studies have begun to explore cognitive functioning in LVAD patients, they have been limited to postoperative cognitive assessments and have not compared these results to baseline preoperative cognitive assessments. In order to further understand the implications of LVADs on HF patient cognition, baseline measurements of cognitive function pre- and post-LVAD implantation are needed. In addition, several research groups have found that a lack of cerebral oxygen saturation perioperatively may increase the risk for neurocognitive dysfunction in patients undergoing surgery for LVAD implantation. Thus, it is imperative to investigate the role of cerebral oximetry during LVAD surgery. Importantly, recent research suggests that perioperative cerebral oxygenation may determine whether or not a patient achieves cognitive rehabilitation post-surgery. Considering that the prevalence of advanced HF patients in need of LVADs is skyrocketing, research in the field of LVAD-related neurocognitive effects is vital in order to optimize cognitive rehabilitation and establish predictive measures for long-term outcomes.

\section{REFERENCES}

1. Lloyd-Jones DM. Lifetime Risk for Developing Congestive Heart Failure: The Framingham Heart Study. Circulation 2002;106:3068-3072.

2. Mcmurray JJV, Pfeffer MA. Heart failure. Lancet 2005;365:1877-1889.

3. Ammar KA et al. Prevalence and prognostic significance of heart failure stages: application of the American College of Cardiology/American Heart Association heart failure staging criteria in the community. Circulation 2007;115: 1563-70.

4. Yau TM et al. Clinical Studies Community support of patients with a left ventricular assist device: The Toronto General Hospital experience. Canadian Journal of Cardiology 2009;25:377-381.

5. Giamouzis G, Triposkiadis F, Butler J, Westermann D, Giannakoulas G. Heart failure. Cardiology Research and Practice 2011;2011:159608.

6. Baker DW, Einstadter D, Thomas C, Cebul RD. Mortality trends for 23,505 Medicare patients hospitalized with heart failure in Northeast Ohio, 1991 to 1997. American Heart Journal 2003;146:258-264.

7. Leening MJG et al. Methods of data collection and definitions of cardiac outcomes in the Rotterdam Study. European journal of epidemiology 2012;27:173-85.

8. Abraham WT, Smith SA. Devices in the management of advanced, chronic heart failure. Nature Reviews Cardiology 2013;10:98-110.

9. Braunwald E. Heart failure. JACC: Heart failure 2013;1:1-20.

10. Picano E, Bruno RM, Ferrari GF, Bonuccelli U. Cognitive impairment and cardiovascular disease: so near, so far. International journal of cardiology 2014;175:21-9.

11. Novak V, Hajjar I. The relationship between blood pressure and cognitive function. Nature reviews. Cardiology 2010;7:686-98.

12. Dardiotis E et al. Cognitive impairment in heart failure. Cardiology Research and practice 2012;2012:595821.

13. Burns A, Zaudig M. Rapid review Mild cognitive impairment in older people. Lancet 2002;360:1963-1965.

14. Fleisher AS, Sowell BB, Gamst AC. Clinical predictors of progression to Alzheimer disease in amnestic mild cognitive impairment. Neurology 2007;68:1588-1595.

15. Gruhn N et al. Cerebral Blood Flow in Patients With Chronic Heart Failure Before and After Heart Transplantation. Stroke 2001;32:2530-2533.

16. Alves TCTF. Localized Cerebral Blood Flow Reductions in Patients With Heart
Failure: A Study Using 99mTc-HMPAO SPECT. Journal of Neuroimaging 2005;15:150-156.

17. Ritchie K, Lovestone S. The dementias. Lancet 2002;360:1759-1766.

18. Bennett SJ, Sauv MJ. Cognitive Deficits in Patients With Heart Failure A Review of the Literature. Journal of Cardiovascular Nursing 2003;18:219-242.

19. Pressler SJ. Cognitive Functioning and Chronic Heart Failure A Review of the Literature (2002 - July 2007). Journal of Cardiovascular Nursing 2008;23:239-249.

20. Vogels RLC et al. Profile of cognitive impairment in chronic heart failure. Journal of the American Geriatrics Society 2007;55:1764-70.

21. Colluci WS, Braunwald E. Pathophysiology of heart failure. In: Zipes DP, editor. Braunwald's Heart Disease: A textbook of cardiovascular medicine. 7th ed. Philadelphia: W.B. Saunders; 2005.

22. Haaland KY. Cardiogenic Dementia. Lancet 1977;1:1171.

23. Arnold JMO, Liu P, Demers C, et al. Canadian Cardiovascular Society consensus conference recommendations on heart failure 2006 : Diagnosis and management. Canadian Journal of Cardiology 2006;22:23-45.

24. Vogels RLC, Scheltens P, Schroeder-tanka JM, Weinstein HC. Cognitive impairment in heart failure : A systematic review of the literature. European Journal of Heart Failure 2007;9:440-449.

25. Rod NH, Andersen I, Prescott E. Psychosocial Risk Factors and Heart Failure Hospitalization: A Prospective Cohort Study. American Journal of Epidemiology 2011;174:672-680.

26. Bennett SJ, Pressler ML, Hays L, et al. Psychosocial variables and hospitalization in persons with chronic heart failure. Prog Cardiovasc Nurs 1997;12:411.

27. Dardiotis E et al. Cognitive impairment in heart failure. Cardiology Research and practice 2012;2012:595821.

28. Onder $\mathrm{G}$ et al. Use of angiotensin-converting enzyme inhibitors and variations in cognitive performance among patients with heart failure. European Heart Journal 2005;26:226-233.

29. Lezak MD, Howieson DB, Bigler ED, and Tranel D. Neuropsychological Assessment. 5th ed. New York: Oxford University Press; 2012.

30. Stein J, Luppa M, Brähler E, König HH, Riedel-Heller SG. The assessment of changes in cognitive functioning: reliable change indices for neuropsychological instruments in the elderly - a systematic review. Dementia and geriatric cognitive disorders 2010;29:275-86.

31. Woodruff BK. Disorders of cognition. Seminars in Neurology 2011;31:18-28.

32. Bauer $L$ et al. A brief neuropsychological battery for use in the chronic heart failure population. European Journal of Cardiovascular Nursing 2012;11:223-30.

33. Chan RCK, Shum D, Toulopoulou T, Chen EYH. Assessment of executive functions: review of instruments and identification of critical issues. Archives of clinical neuropsychology : the official journal of the National Academy of Neuropsychologists 2008;23:201-16.

34. Hoth KF, Poppas A, Moser DJ, Paul RH, Cohen RA. Cardiac dysfunction and cognition in older adults with heart failure. Cognitive and Behavioral Neurology 2008;21:65-72.

35. Incalzi RA et al. Verbal Memory Impairment in Congestive Heart Failure. Journal of Clinical and Experimental Neuropsychology 2003;25:14-23.

36. Mapelli $D$ et al. Neuropsychological profile in a large group of heart transplant candidates. PloS one 2011;6:e28313.

37. Foster ER et al. Executive Dysfunction and Depressive Symptoms Associated With Reduced Participation of People With Severe Congestive Heart Failure. American Journal of Occupational Therapy 2011;65:306-313.

38. Athilingam $\mathrm{P}$ et al. Montreal Cognitive Assessment and Mini-Mental Status Examination compared as cognitive screening tools in heart failure. Heart \& Lung 2011;40:521-9.

39. Putzke JD et al. Neuropsychological Functioning Among Heart Transplant Candidates : A Case Control Study. Journal of Clinical and Experimental Neuropsychology 2000;22:95-103.

40. Grubb NR, Simpson C, Fox KA. Memory function in patients with stable, moderate to severe cardiac failure. American Heart Journal 2000;140:E1E5.

41. Hachinski V et al. National Institute of Neurological Disorders and StrokeCanadian Stroke Network vascular cognitive impairment harmonization standards. Stroke 2006;37:2220-41.

42. Petrucci RJ et al. Neurocognitive assessments in advanced heart failure patients receiving continuous-flow left ventricular assist devices. The Journal of Heart and Lung Transplantation 2009;28:542-9.

43. Tanne $D$ et al. Cognitive functions in severe congestive heart failure before and after an exercise training program. International journal of cardiology 2005;103:145-9. 
44. Trojano L et al. Cognitive impairment: a key feature of congestive heart failure in the elderly. Journal of neurology 2003;250:1456-63.

45. Schlösser RGM, Wagner G, Sauer H. Assessing the working memory network: studies with functional magnetic resonance imaging and structural equation modeling. Neuroscience 2006;139:91-103.

46. Wen $W$ et al. Discrete neuroanatomical networks are associated with specific cognitive abilities in old age. The Journal of Neuroscience 2011;31:120412.

47. Scotia N et al. Subcortical Dementia : A Neurobehavioral Approach. Brain and Cognition 1996;249:230-249.

48. Bauer LC, Johnson JK, Pozehl BJ. Cognition in heart failure: an overview of the concepts and their measures. Journal of the American Academy of Nurse Practitioners 2011;23:577-85.

49. Hjelm $C$ et al. The influence of heart failure on longitudinal changes in cognition among individuals 80 years of age and older. Journal of Clinical Nursing 2012;21:994-1003.

50. Gunstad J et al. Cardiac Rehabilitation Improves Cognitive Performance in Older Adults With Cardiovascular Disease. Journal of Cardiopulmonary Rehabilitation 2005;25:173-176.

51. Tanne D et al. Cognitive functions in severe congestive heart failure before and after an exercise training program. International Journal of Cardiology 2005;103:145-9.

52. Harkness K, Demers C, Heckman G, McKelvie RS. Screening for cognitive deficits using the Montreal cognitive assessment tool in outpatients $\geq 65$ years of age with heart failure. The American Journal of Cardiology 2011;107, 1203-7.

53. Roman DD et al. Memory Improvement Following Cardiac Transplantation. Journal of Clinical and Experimental Neuropsychology 1997;19:692-697.

54. Nash DT, Fillit H. Cardiovascular disease risk factors and cognitive impairment. The American Journal of cardiology 2006;97:1262-5.

55. Pase MP et al. Blood pressure and cognitive function: the role of central aortic and brachial pressures. Psychological Science 2013;24:2173-81.

56. Qiu C, Winblad B, Fratiglioni L. Low diastolic pressure and risk of dementia in very old people: a longitudinal study. Dementia and Geriatric Cognitive Disorders 2009;28:213-9.

57. Rose KM et al. Orthostatic hypotension and cognitive function: the Atherosclerosis Risk in Communities Study. Neuroepidemiology 2010;34:1-7.

58. Girouard H, ladecola $\mathrm{C}$. Neurovascular coupling in the normal brain and in hypertension, stroke, and Alzheimer disease. Journal of Applied Physiology 2006;100:328-35.

59. Aaslid R, Lindegaard KF, Sorteberg W, Nornes H. Cerebral autoregulation dynamics in humans. Stroke 1989;20:45-52.

60. Lipsitz LA, Mukai S, Hamner J, Gagnon M, Babikian V. Dynamic Regulation of Middle Cerebral Artery Blood Flow Velocity in Aging and Hypertension. Stroke 2000;31:1897-1903.

61. Novak V, Novak P, Spies JM, Low PA. Autoregulation of Cerebral Blood Flow in Orthostatic Hypotension. Stroke 1998;29:104-111.

62. Hu K et al. Altered Phase Interactions between Spontaneous Blood Pressure and Flow Fluctuations in Type 2 Diabetes Mellitus: Nonlinear Assessment of Cerebral Autoregulation. Physica A 2008;387:2279-2292.

63. Novak $V$ et al. Multimodal pressure-flow method to assess dynamics of cerebral autoregulation in stroke and hypertension. Biomedical Engineering 2004;3:39.

64. Rose KM et al. Orthostatic hypotension predicts mortality in middle-aged adults: the Atherosclerosis Risk In Communities (ARIC) Study. Circulation 2006;114:630-6.

65. Fedorowski $A$ et al. Consequences of orthostatic blood pressure variability in middle aged men. J. Hypertens. 2010;28:551-559.

66. Kahinen-Vare $\mathrm{M}$ et al. Left ventricular hypertrophy and blood pressure as predictors of cognitive decline in old age. Aging Clin. Exp. Res. 2004;16:147152.

67. Reitz C, Tang MX, Manly J, Mayeux R, Luchsinger JA. Hypertension and the risk of mild cognitive impairment. Arch. Neurol. 2007;64:1734-1740.

68. Yap PLK, Niti M, Yap KB, Ng TP Orthostatic hypotension, hypotension and cognitive status: early comorbid markers of primary dementia? Dementia and Geriatric Cognitive Disorders 26, 239-46 (2008).

69. Zuccala $\mathrm{G}$ et al. Hypotension and cognitive impairment: selective association in patients with heart failure. Neurology. 2011;57:1986-1992.

70. Samuels, M. a Can cognition survive heart surgery? Circulation 2006;113: 2784-6.

71. de la Torre JC. Cardiovascular risk factors promote brain hypoperfusion leading to cognitive decline and dementia. Cardiovascular Psychiatry and Neurology 2012;2012:367516.
72. Busatto GF. Regional cerebral blood flow reductions, heart failure and Alzheimer's disease. Neurological Research 2006;28:579-587.

73. Zuccalà G, Cattel C, Manes-Gravina E, et al. Left ventricular dysfunction: A clue to cognitive impairment in older patients with heart failure. J Neurol Neurosurg Psychiatry. 1997;63:509-512.

74. Putzke JD, Williams MA, Rayburn BK, Kirklin JK, Boll TJ. The relationship between cardiac function and neuropsychological status among heart trans plant candidates. J Card Fail. 1998;4:295-303.

75. Bruce KM, Yelland GW, Smith JA, Robinson SR. Recovery of cognitive function after coronary artery bypass graft operations. The Annals of Thoracic Surgery 2013;95:1306-13.

76. Newman MF et al. Longitudinal Assessment of Neurocognitive Function After Coronary-Artery Bypass Surgery. New England Journal of Medicine 2011;344:395-403.

77. Zeger SL, Ph D, Mckhann GM. Cognitive and Neurologic Outcomes after Coronary-Artery Bypass Surgery. New England Journal of Medicine 2012;366:250-257.

78. Roselli EE et al. Adverse events during reoperative cardiac surgery: frequency, characterization, and rescue. The Journal of Thoracic and Cardiovascular surgery 2008;135:316-23, 323.e1-6.

79. Barbut $D$ et al. Cerebral emboli detected during bypass surgery are associated with clamp removal. Stroke 1994;25:2398-2402.

80. Barbut D, Yao FS, Hager DN, Kavanaugh P, Trifiletti RR, Gold JP. Compassion of Transcranial Doppler ultrasonography to monitor emboli during coronary artery bypass surgery. Stroke. 1996;27:87-90.

81. Fischer GW, Silvay G. Cerebral oximetry in cardiac and major vascular surgery. HSR Proceeding in Intensive Care and Cardiovascular Anesthesia 2010;2.

82. Vretzakis $\mathrm{G}$ et al. Cerebral oximetry in cardiac anesthesia. Journal of Thoracic disease 2014;6:S60-9.

83. Yao FSF, Tseng CC, Ho CY, Levin SK, Illner P. Cerebral oxygen desaturation is associated with early postoperative neuropsychological dysfunction in patients undergoing cardiac surgery. Journal of Cardiothoracic and Vascular Anesthesia 2004;18:552-558.

84. Murkin JM et al. Monitoring brain oxygen saturation during coronary by pass surgery: a randomized prospective study. Anesthesia and Analgesia. 2007; 104:51-58.

85. van Harten AE, Scheeren TW, Absalom AR. A review of postoperative cognitive dysfunction and neuroinflammation associated with cardiac surgery and anaesthesia. Anaesthesia 2012;67:280-93.

86. Slater JP et al. Cerebral oxygen desaturation predicts cognitive decline and longer hospital stay after cardiac surgery. The Annals of Thoracic Surgery 2009;87:36-44, discussion 44-5. 